\title{
O processo educacional brasileiro: um breve olhar ético e histórico acerca do sujeito afrodescendente
}

\author{
Adriana dos Reis Silva ${ }^{1}$ \\ adrianasier@yahoo.com.br
}

Maysa de Pádua Teixeira²
maysapadua@yahoo.com.br

\section{Resumo}

A proposta deste trabalho é construir um discurso, abordando aspectos éticos e diferenciais envoltos no contexto educacional trilhado pelos afrodescendentes brasileiros. Afinal, é comum vivenciar nas escolas, desde outrora, a marcante presença do preconceito racial em relação aos negros. Pensamos que compreender a diversidade étnica e cultural do Brasil pode ser uma maneira de romper com as barreiras impostas pelas diferenças. Dessa forma, ao longo deste estudo, buscamos uma compreensão dos mecanismos que engendraram o processo educacional brasileiro, bem como a problemática da inserção do negro nessa realidade. Esclarecemos que os elementos discursivos estabelecidos nesta pesquisa são corroborados por fatos históricos suscitados pela criação e divulgação de determinados estereótipos acerca do povo africano e promovidos a partir do imaginário socioeconômico brasileiro.

Palavras-chave: Educação; história; etnia; afrodescendentes.

\footnotetext{
${ }^{1}$ Doutoranda do Programa de Pós-Graduação em Letras da Pontifícia Universidade Católica de Minas Gerais (PUC/MG).

${ }^{2}$ Doutoranda do Programa de Pós-Graduação em Letras da Pontifícia Universidade Católica de Minas Gerais (PUC/MG).
}

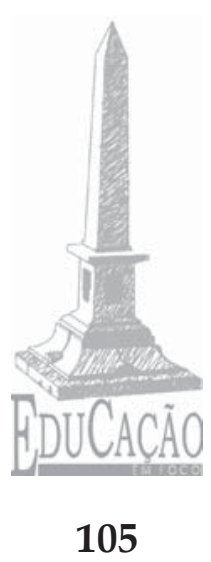

Ano 12 - n. 14 - dezembro 2009 - p. 105-121 


\section{Introdução}

Vivenciamos tacitamente a marcante presença do preconceito racial em relação aos negros nas escolas brasileiras. Desde outrora, quem nunca ouviu: "só podia ser preto mesmo..." "o cabelo não é ondulado, é pixaim" "Macaca (o)!" ${ }^{3}$ Sob esses apontamentos, pretendemos construir um discurso, abordando aspectos éticos e históricos com o intuito de se apreender o percurso trilhado pelos afrodescendentes brasileiros em relação à sua inserção no contexto educacional brasileiro. Acreditamos que, ao compreender a diversidade étnica e cultural brasileira, podem surgir meios para se romper com as barreiras impostas pelas diferenças.

Nesse sentido, nossa abordagem acerca da problemática sofrida pelo negro no âmbito educacional será embasada pela ótica de Soligo e Wechsler (2002), Paiva (2004), Abramovay e Castro (2006), dentre outros.

Na atualidade, têm sido desenvolvidas inúmeras pesquisas relevantes, buscando resolver os impasses a respeito da racialização. E se isso é preponderante, induz que existem relações negativas advindas da pluralidade racial no cotidiano escolar. Portanto, modificar esse contexto sociocultural é uma tarefa árdua tanto para governantes e profissionais da educação como para os sujeitos militantes das causas raciais, que perseverantemente trabalham por um país sem desigualdades.

O cientista político Michael Hanchard (1996), em resposta à crítica feita a respeito do seu livro Orpheus and power, afirma que essa obra permite a seguinte reflexão:

Primeiramente, argumento que a desigualdade racial no Brasil pode ser pensada como um processo de hegemonia racial. Nesse processo, práticas racialmente discriminatórias com respeito à educação, ao emprego e a outros aspectos da vida, coexistem lado a lado com a falsa promessa de igualdade

${ }^{3}$ Modo de se referir a uma pessoa negra.

Ano 12 - n. 14 - dezembro 2009 - p. 105-121 
racial expressa na ideologia da democracia racial. Em conseqüência, muitos brasileiros brancos, tanto quanto outros de outras cores, nunca reconheceram a existência de discriminação racial contra afro-brasileiros no país. Aqueles dispostos a reconhecerem sua existência mantêm muitas vezes que o racismo brasileiro é qualitativamente distinto e menos prevalente quando comparado ao racismo dos Estados Unidos. Este sentimento é confirmado, em parte, pela pesquisa do Data Folha sobre atitudes raciais em 1995, que caracterizou as atitudes brasileiras de "racismo cordial" (HANCHARD, 1996, p. 227).

Notamos, portanto, que a desigualdade racial no Brasil é algo complexo e trata-se de um legado sobre o qual o país não quer discutir, salvo exceções. Entretanto, para nós, é um assunto provocador, pois mostra as faces dos conflitos entre etnias.

Com a Lei de Diretrizes e Bases da Educação Nacional, verificamos a preocupação governamental brasileira em se fazer conhecer a história de um povo com uma tradição singular, como os africanos. Com essa finalidade, foi instituída para o ensino básico a obrigatoriedade curricular de propagar a história e cultura afrobrasileira (lei n. 10.639, de 9 de janeiro de 2003). Segundo as diretrizes estabelecidas pelos Parâmetros Curriculares Nacionais para o Ensino Básico,

trazer a ética para o espaço escolar significa enfrentar o desafio de instalar, no processo de ensino e aprendizagem que se realiza em cada uma das áreas de conhecimento, uma constante atitude crítica, de reconhecimento dos limites e possibilidades dos sujeitos e das circunstâncias, de problematização das ações e relações e dos valores e regras que os norteiam (BRASIL, 1998, p. 61).

Logo, observamos a necessidade de mudanças circunstanciais, resgatando os valores sociais e culturais que de certa forma parecem adormecidos no âmbito educacional. Encontrar caminhos para

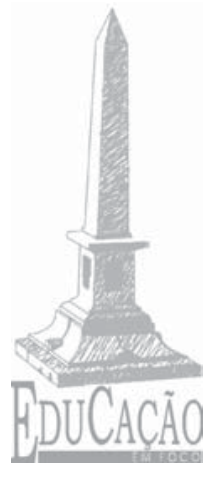

107 
desconstruir os estereótipos criados pela sociedade em relação aos africanos e aos afrodescendentes brasileiros surge como uma maneira eficaz de desmistificar muitos (pré)conceitos instaurados em nossa cultura.

Olhar e desvendar os mistérios de uma civilização milenar como a africana se faz necessário ao mesmo tempo em que transpomos as diversidades socioculturais existentes no meio educacional brasileiro. Assim, acreditamos que se houver o regaste do entendimento acerca das questões como: o papel da escola, a questão do diferente e a atitude ética, será possível construir uma ruptura no Brasil.

\section{Um breve olhar histórico}

Segundo Hernandez (2005), em estudos realizados sobre a África, particularmente entre as décadas finais do século XIX e meados do século XX, permanece entre nós a crença em noções equivocadas e preconceituosas decorrentes em sua maioria de interpretações inadequadas da história africana, quando não de seu próprio desconhecimento.

Ainda de acordo com a referida autora, as pesquisas efetuadas acerca desse continente

foram antes de tudo, instrumento de política nacional, contribuindo de modo mais ou menos direto para uma rede de interesses políticos econômicos que ligava as grandes empresas comerciais, as missões, às áreas de relações exteriores e o mundo acadêmico (HERNANDEZ, 2005, p. 18).

Logo, percebemos que o ocidente constrói uma visão estereotipada em relação à África. E isso ocorre desde o Iluminismo (século XVIII), quando os preceitos europeus eram preponderantes em terras brasileiras. Nessa direção, Sodré afirma que

[...] triunfava aqui a ideologia européia do progresso infinito com base na civilização industrial. Passava-se a explicar o mundo físico e humano por leis matemáticas e

Ano 12 - n. 14 - dezembro 2009 - p. 105-121 
mecânicas, os conceitos darwinianos e spencerianos de evolução estabeleciam padrões de pensamento em níveis diversos. [...] Nesse ambiente de importação de idéias, as teorias raciais transformavam-se em ferramentas para a invenção de uma identidade nacional (SODRÉ, 1999, p. 85).

O trabalho elaborado por Paiva mostra que a historiografia brasileira revisou temas como escravidão, entre outros, segundo a versão do "imaginário do tronco": [...] além de uma pretensa incapacidade natural de negros e mestiços para atividades intelectuais, eles nunca tiveram acesso à escrita e à leitura e nem interessavam por isso (PAIVA, 2003, p. 24).

De acordo com Paiva, a interpretação mencionada acima nada mais é do que algo "ideologizado", criado "à revelia das evidências arquivísticas da escravidão no Brasil" (PAIVA, 2003, p. 26). A verdade é outra, contrária a essa concepção, pois estudos recentes mostram que houve o processo de letramento entre negros da América portuguesa durante os séculos XVI a XIX.

Fonseca (2005) entende que pesquisas realizadas ainda nos séculos XVIII e XX mostram que o vocábulo "negro" não aparece. Nesse sentido, para designar o ser dessa etnia, eram utilizados termos como: pretos, pardos, mulatos, crioulos, mestiços, africanos. A inserção desses léxicos numa enunciação era dada de acordo com o lugar social e o aspecto racial representado pela posição ocupada pelos sujeitos na sociedade (MATTOS, 1998). Em face disso, a diversidade terminológica seria parte integrante de um processo de dominação cujo objetivo seria uma segmentação, impossibilitando uma uniformização que poderia ter no embate político (MUNANGA, 1999).

Em trabalho realizado por Martins (2001), verificamos que existem questões que têm dificultado o avanço na abordagem dos temas de interesse dos afrodescendentes nos últimos 50 anos. Uma delas é a consolidação do conjunto ou sistema de ideias políticas, sociais e econômicas dos grupos dominantes na sociedade e na cultura nacional sobre a "democracia racial". Ideário que impediu em diversos

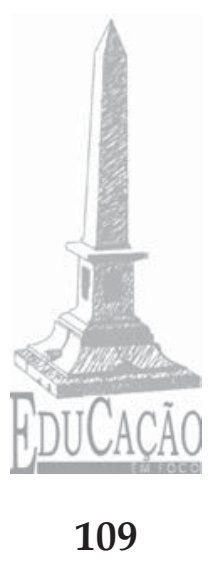


setores uma reflexão mais aprofundada e problematizadora sobre as estruturas étnicas vigentes na sociedade e sobre os problemas daí decorrentes no trato com a cultura e a educação.

Complementando a discussão de democracia racial, é pertinente recordarmos que a base nacional brasileira é miscigenada e, por conseguinte, nega esta particularidade. Logo, a miscigenação biológica demonstrada no Brasil é tratada com propósitos políticos. Para simbolizar esse ideário, a representação da Casa Grande e Senzala tornou-se um modelo não somente da interpretação social, como dos propósitos políticos, esquecendo então, talvez de modo proposital, as relações de produção representadas pelo trabalho escravo.

Com base em curso proferido pelo professor Marcus Vinicius Fonseca ${ }^{4}$, é pertinente dizermos que desde a colonização do Brasil, há uma relação forte entre os negros e a educação. As práticas passadas para os escravos brasileiros já eram uma forma de escolarização. O negro esteve presente na base da própria construção educacional brasileira, quer dizer, em todo momento.

Para esclarecer a temática da segregação racial brasileira, é relevante retomarmos o estudo de Martins (2001), no qual se pode observar que um dos fatos que contribuíram inicialmente para a desigualdade racial brasileira foi a inclusão de africanos e descendentes em nosso país sob a condição de escravo. Podemos afirmar, com isso, que as desigualdades raciais vividas na contemporaneidade são decorrência de um passado escravocrata. Ainda segundo o autor, a “escravidão moderna" é um modo extremamente marcante de exclusão socioeconômica, criado pelo ser humano detentor do poder.

E, ainda, a falta de conhecimento acerca da história e cultura dos afrodescendentes "escamoteadas" pelo oficial processo historiográfico brasileiro cooperou surpreendentemente para a não valorização desse povo. A população do Brasil desconhece a contribuição dada pelo negro para o desenvolvimento de nosso país. Nesse sentido, percebemos que no ambiente escolar, enquanto lu${ }^{4}$ FONSECA, M. V. II Curso de Aperfeiçoamento da África e das Culturas Afro-Brasileiras, 2007UFMG (informação oral). 
gar de práticas educacionais, os valores assimilados pelos brancoeuropeus são os que prevalecem nos livros didáticos. Nós, que atuamos em sala de aula, ainda percebemos esse contexto.

Nesse mesmo sentido, Pereira (2006) destaca que a ausência de memórias coletivas restringe a educação a um pólo eurocêntrico, em que as diferentes figuras de linguagem alojam o preconceito e atitudes discriminatórias que permeiam todo o cotidiano escolar, inclusive os instrumentos de trabalho, sejam materiais didáticos, materiais visuais ou audiovisuais. De acordo com essa autora, todo o material "está carregado de conteúdos viciados, depreciativos e preconceituosos em relação a questões de gênero, da comunidade indígena e da comunidade negra" (PEREIRA, 2006, p. 37).

A respeito das formas "veladas" de difusão e manutenção do preconceito de cor também infiltradas no contexto escolar, parecenos interessante mencionar os apontamentos de um trabalho elaborado por nós ao final de uma disciplina cursada na Pós-Graduação ${ }^{5}$. Nesse trabalho, partimos da observação de Simon: "tudo que tem sido dito e escrito em torno à escravidão negra, cristalizou-se em fórmulas, em frases ou locuções que adquirem valor-verdade, à força de serem repetidas por muitas gerações" (SIMON, 1995, p. 12).

Essas fórmulas são os provérbios, ditados, comparações, piadas que, ao mencionarem a raça negra, geralmente ressaltam a condição inferior que o negro ocupa na sociedade. A intenção delas é fazer crer que essa inferioridade é natural, característica mesmo da raça, motivo pelo qual o negro deve se submeter ao branco e servir-lhe no que lhe é exigido. Por outro lado, as metáforas criadas em torno do referente "negro" associam-no ao mal, ao sofrimento, ao trabalho pesado. De acordo com Paiva (1998), é comum pessoas da própria etnia dizer que "a coisa está preta" ou utilizando o verbo "denegrir", que significa, em seu sentido literal, tornar negro, escuro, enegrecer, escurecer. No sentido metafórico, significa manchar, macular, desacreditar, desabonar, difamar.

A análise linguística desses ditos populares nos mostrou que

${ }^{5}$ Silva e Teixeira (2009). 
eles se apoiam em uma crença cristalizada a partir do processo de racialização brasileiro de que a etnia negra é inferior à branca dominante. Essa crença parece justificar o tratamento desigual dado aos afrodescendentes em nosso país, sobretudo no que diz respeito às condições de trabalho, estudo e moradia.

De maneira mais ou menos explícita, os ditos populares evidenciam a imagem do negro em nossa sociedade ao mesmo tempo que, ao serem repetidos e ensinados de geração a geração, perpetuam a crença compartilhada de subordinação de uma etnia à outra.

Ainda sobre a questão da manutenção e divulgação do preconceito de cor, podemos citar a pesquisa elaborada por Silva (2009) a respeito das narrativas televisivas brasileiras que mostram:

[...] a preocupação/despreocupação com o Outro - o africano, o afro descendente, o diferente, aquele que, na reprodução midiática, na maioria das vezes é o maltratado pela corte e seus súditos, o que não é fada, que representa somente o malévolo, entre outras aparições grotescas (SILVA, 2009, p. 14).

Para essa pesquisa, a autora selecionou cenas de duas novelas veiculadas pela Rede Globo de Televisão, que foram: “Duas Caras" e "O Profeta". Em ambas, há núcleos compostos por personagens negros que adquiriram certo relevo para o desfecho das tramas. Isso não é muito comum nas mídias brasileiras, afinal, os papéis de destaque sempre cabem aos brancos.

Ao final de seu trabalho, Silva (2009) observou que a racialização incutida nessas tramas a princípio tenta quebrar a corrente do preconceito racial. No entanto, acaba cometendo os mesmos erros advindos do meio social - deixa de lado o que é importante para combater o racismo e investe no conflito entre casais, famílias, colegas de escola ou coisas do tipo e ainda acentua os estereótipos negativos sobre os negros, como acontece, por exemplo, com a sensualidade que caracteriza a personagem Gislaine, que se encaixa no perfil de "mulata" sensual. O mesmo acontece com Evilásio Caó. Ele

\section{2}

Ano 12 - n. 14 - dezembro 2009 - p. 105-121 
também se assume como negro, mas seu personagem traz o padrão estereotipado do negro sensual. Corroborando esse fato, Lázaro Ramos, ator que representou o personagem Evilásio, expõe: “Malhei, malhei, malhei. Acho que o corpo tem que estar a serviço do personagem mesmo. É para ser gostosinho? Então, vamos lá!"6

Diante desse estado de coisas, Silva (2009) questiona se o públi$\mathrm{co} /$ telespectador brasileiro está realmente preocupado com o outro, isto é, com os problemas raciais. Afinal, é ele (o público/ telespectador) que faz uma trama de telenovela acontecer, pois se a narrativa não estiver satisfazendo seus anseios, logo o autor muda a trama, mata algum personagem e até mesmo termina a novela antes da época prevista. Em conclusão, Silva afirma que:

Sendo assim, fica claro que não basta só o autor (ou direção de uma telenovela) querer mudar algo, falar sobre algo que preocupa a sociedade. A sociedade tem que querer e reivindicar estas mudanças, ou seja, é ela que tem que buscar as relações igualitárias e uma política eficaz anti-racista, e ainda, ver e demandar, dos autores e dos aparelhos midiáticos, histórias verossímeis em relação ao que o negro viveu e/ ou que esta vivendo na atualidade (SILVA, 2009, p. 118).

\section{Alguns conceitos}

De acordo com Boff (2003), somente há ética no singular, pertencendo essa à natureza humana, estando presente em cada pessoa. Já a moral encontra-se no plural, pois são as distintas formas de expressão cultural da ética. Ética vem do grego ethos (com " $\mathrm{e}^{\text {" }}$ minúsculo), significando morada - abrigo permanente, seja de animais (estábulo) ou de seres humanos (casa). Ainda conforme o autor, a morada deve ser cuidada e sempre retrabalhada. Essa menção feita por Boff deveria ser uma atitude constante da práxis humana e, nesse caso específico, uma regra de ação para tudo que for associado ao processo educacional brasileiro.

\footnotetext{
${ }^{6}$ Esse depoimento foi retirado do Jornal Estado de Minas, Belo Horizonte, 18 mai. 2008. Caderno TV.p. 02.
}

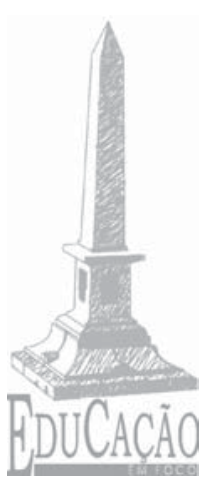

113 
Ethos ("E" maiúsculo) pode se traduzir como moral - conjunto dos meios ordenados ao fim (bem/autorrealização). Moral (mosmores em latim) significa os costumes e valores de uma determinada cultura. Como são muitos e próprios de cada cultura, tais valores e hábitos fundam várias morais.

Dussel (1998) questiona como universalizar um discurso ético que englobe a todos sem diferenças. Ele enfatiza essa questão, afirmando que chegamos à universalidade somente se partimos de uma parcialidade dos últimos, daqueles que estão de fora, dos que têm seu ser negado (BOFF, 2003).

Nessa perspectiva, Boff corrobora que a ética deve originar-se do outro, não simplesmente do outro, porém "do outro mais outro", aquele que é pobre, excluído, negro, indígena, enfim, o outro que é discriminado pelos mais diversos preconceitos. Assim, podemos pressupor que uma ética voltada para questões vinculadas à educação possa ser postulada num “[...] saber abrir-se ao outro, e levá-lo a sério (responsabilidade) em favor do outro ante o sistema" (DUSSEL, 1986, p. 51-52).

Logo, se observamos a socialização (processo que é fundamental para se depreender no âmbito escolar) através da ampliação do amor, e este como sendo o fundamento do fenômeno social, seremos capazes de mudar a condição revelada pelo outro (lugar marcado pela diferença). Contudo, se não houver amor, o social é destruído. Persistindo na falta desse sentimento, a forma de agregação forçada ganha espaço, e a dominação e a violência de uns contra os outros também.

\section{O espaço escolar}

De acordo com Ferreira: "[...] a aprendizagem de valores na escola depende do cultivo de princípios que facultem reconhecer no outro a sua humanidade; daí o exercício do cuidado de se educar para a vida e não para algumas instituições" (FERREIRA, 2006, p. 61).

Assim, a arte de educar implica um compromisso ético e moral na constante procura pelo conhecimento por parte do educador,

\section{4}

Ano 12 - n. 14 - dezembro 2009 - p. 105-121 
ou ainda, se constitui num processo de responsabilidade social para a construção do sujeito, pois há a necessidade de fazer a diferença diante de situações de antagonismos e tabus sociais instaurados no âmbito educacional.

Em trabalho realizado por Abramovay e Castro (2006), constatamos que os alunos negros incluem-se e são incluídos no conjunto dos diferentes, eles são vistos e considerados como "os outros" até mesmo para a maioria dos alunos negros.

Para Soligo e Wechsler "o autoconceito de crianças negras, definido como identidade, encontra mecanismos de expressão do preconceito racial entre os alunos, que permeiam as relações e determinam o discurso da criança negra sobre si mesma" (SOLIGO; WECHSLER, 2002, p.17-30).

A partir desse excerto, questionamos: uma escola diferenciada, com propósitos focados na busca de uma "educação ética e moral”, é possível? Achamos que se houver ações efetivas comprometidas com o respeito mútuo, que propiciem condições para que crianças e jovens se tornem sujeitos atuantes, que valorizem o "outro", compreendendo e aceitando suas diferenças, será um bom começo para se idealizar o processo educativo proposto acima. Necessitamos de apreender que a base de uma cultura é dada a partir de preceitos educacionais.

Portanto, ainda segundo as autoras acima citadas, é importante contextualizar o cenário onde se insere o diferente para então querer aceitar o desafio existente e sair da mesmice, buscando conhecer mais o outro: questionar igualdades pautadas em desigualdades e aprender a lidar e cultivar a diversidade sem assimetrias, ou, como bem frisam Gomes e Silva (2002), reconhecer as diferenças.

\section{Mudanças}

Na condição de emancipadora dos indivíduos, a escola precisa se posicionar como instituição social responsável pela formação e realização do ser humano, garantindo uma convivência saudável,

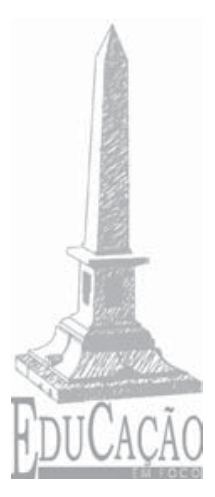

115 
respeitosa, responsável, prudente e tolerante entre todos.

Em Abramovay e Castro (2006), notamos que o grande desafio, no que se refere à diversidade instaurada no campo educacional e na formação dos professores, é como imaginá-la em sua dinâmica e articulação no âmbito da educação escolar e fora dele também para não convertê-la em "metodologias e técnicas de ensino para os ditos 'diferentes'” (ABRAMOVAY; CASTRO, 2006, p. 88). Isso quer dizer que temos que tomar a diferença como parte dos processos educacionais, sendo que esses processos são construídos através das relações socioculturais existentes entre os seres humanos e os atores sociais. Por conseguinte, é possível concluir que os profissionais vinculados às áreas educacionais trabalham com as "semelhanças e as diferenças, as identidades e as alteridades, o local e o global”.

Então, é relevante para o educador, antes de criar novas metodologias, reconhecer a diversidade através do contexto histórico, social, político e cultural do Brasil e se manter posicionado em relação às ações afirmativas que se oponham a qualquer manifestação discriminatória.

O Brasil é um país de afrodescendentes. Estudar e valorizar a cultura africana é também valorizar e aceitar o nosso país, pois só assim iremos construir um Brasil mais justo, tendo o sentimento de unidade difundido entre nós. É importante lembrar que a questão racial brasileira não envolve somente negros ou pessoas com o tom de pele escuro, afinal essa é uma "terra" cujas bases provêm da miscigenação de muitos povos. Logo, o grande embate do contexto educacional é instituir-se como um espaço social igualitário. Então, "um desafio à escola, se engajada em uma educação anti-racista, é buscar dialogar sobre uma outra história dos/das oprimidos/as, indo além das vitimizações" (ABRAMOVAY; CASTRO, 2006, p. 35).

\section{Considerações finais}

Notamos que existe a possibilidade de construção de uma sociedade pautada na ética, muito mais que nos aspectos legal ou moral. 
Porém, para isso, é necessário um efetivo trabalho na escola em busca

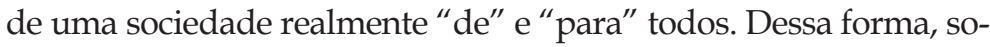
mente preparando a geração atual de jovens, mudaremos a mentalidade dominante hoje. E se o homem é a morada do ethos, a resposta para tudo está se não no homem, na sua educação, nos valores transmitidos, pressupondo que a escola deve assumir para si o desafio de educar para a questão racial, para o diferente, enfim, para o social.

O desafio, então, é o de orientar e educar os indivíduos para que num dado momento eles possam, na condição de sujeitos, transgredirem os valores de uma cultura já estabelecida e reforçada, principalmente quando lhes é negado o direito de ser, escolher e saber. Portanto, a escola precisa se orientar para a promoção da autovalorização, da autoestima e da autorrealização dos estudantes, reconhecendo-os enquanto sujeitos de desejos, direitos, história e perspectivas, que constroem e reconstroem a cultura, o conhecimento, além de o ressignificar para uma educação com liberdade e para o exercício da cidadania.

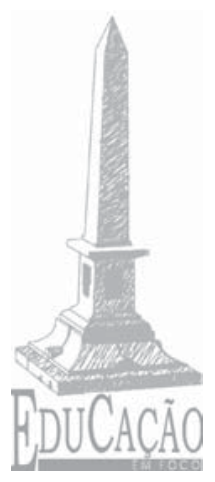

117 


\section{Referências}

ABRAMOVAY, M.; CASTRO M. G. Relações raciais na escola: reprodução de desigualdades em nome da igualdade. Brasília: Unesco, Inep. Disponível em: <http:/ / unesdoc.unesco.org/ images/0014/001459/145993por.pdf>. Acesso em: 21 mar. 2011.

BOFF, L. Ethos mundial: um consenso mínimo entre os humanos. Rio de Janeiro: Sextante, 2003.

DUSSEL, E. Ética comunitária. Petrópolis: Vozes, 1986. p. 51-52.

HANCHARD, M. Resposta a Luiza Bairros. Afro-Ásia, Bahia, v. 18, p. 227-233, 1996. Disponível em: <http:/ / www.afroasia.ufba.br/pdf/afroasia_n18_p227.pdf>. Acesso em: 10 out. 2008.

HERNANDEZ, L. L. A África na sala de aula. São Paulo: Selo Negro, 2005.

LOPES, V. N. Educação escolar e inclusão étnico-racial. In: SANGER, D. dos S. Educação sem descriminação. Viamão: Secretária de Educação de Viamão, 2006. v. 1. p. 25-32. (Coleção Educação Sem Discriminação)

MATTOS, H. M. Das cores do silêncio: o significado da liberdade no sudeste escravagista. Rio de Janeiro: Nova Fronteira, 1998.

MORENO, C. I. Educar em valores. São Paulo: Paulinas, 2001.

MUNANGA, K. Rediscutindo a mestiçagem: identidade nacional versus identidade negra. Petrópolis: Vozes, 1999.

\section{8}


PAIVA, E. F. Leituras (im)possíveis: negros e mestiços leitores na América portuguesa. In: COLÓQUIO INTERNACIONAL: POLÍTICA, NAÇÃO E EDIÇÃO, 2003, Belo Horizonte. Caderno de resumos... Belo Horizonte: Programa de Pós-graduação em História, 2003. v. 1. p. 24-34.

PAIVA, V. M. Metáforas Negras. In: (Org.) Metáforas do Cotidiano. Belo Horizonte: UFMG, 1998. p. 105-119. Disponível em: <http://www.veramenezes.com/metaforas.htm>. Acesso em: 25 out. 2007.

BRASIL. Ministério da Educação. Parâmetros Curriculares Nacionais. Secretária de Educação Fundamental. Brasília: MEC/SEF,1998.

PEREIRA, L. R. B. Educação afro-brasileira: ação para uma educação inclusiva. In: SANGER, D. dos S. Educação sem discriminação. Viamão: Secretária de Educação de Viamão, 2006. v.1. p. 33-42. (Coleção Educação Sem Discriminação).

SILVA, A. R. A construção da personagem afro-descendente na telenovela brasileira sob uma perspectiva discursiva. Dissertação (Mestrado em Letras: Língua Portuguesa) - Faculdade de Letras, Pontifícia Universidade Católica de Minas Gerais. 2009.

SILVA, A. R.; TEIXEIRA, M. de P. Topoï, provérbios e divulgação do preconceito de cor. Parlatorium Revista Eletrônica da Faminas, Belo Horizonte, v. 4, 2009, p. 96-107. Disponível em: <http:/ / www.faminasbh.edu.br/revistaeletronica/ index.php?page=edicoes_anteriores> Acesso em: 10 fev. 2010.

SIMON, M. L. M. Discurso repetido a propósito da escravidão africana. Revista Philologus, Rio de Janeiro, v. 3, p. 12-18, 1995.

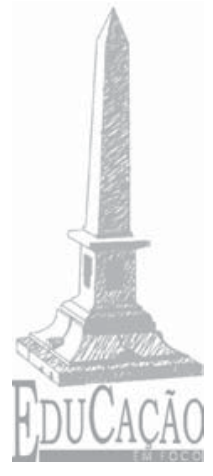


SODRÉ, M. Claros e escuros: identidade, povo e mídia no Brasil. Petrópolis: Vozes, 1999. 272p.

SOLIGO, A. F.; WECHSLER, S. M. Crianças negras e professoras brancas: um estudo de atitudes. Escritos sobre Educação, Brasília, n. 1, p. 17-30, dez. 2002.

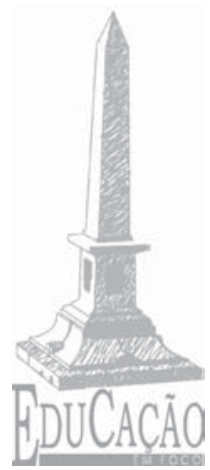




\title{
The brazilian educational process: a short ethical and historical look to the african descendant subject
}

\begin{abstract}
The purpose of this work is to make a speech, addressing ethical and differential wrapped in the educational context trailed by African descendants in Brazil. Nowadays, it is a common experience in shools the strong presence of racial prejudice toward africans. We believe that understanding the ethnic and cultural diversity of Brazil may be a way to break the barriers imposed by differences. Thus, throughout this study, we try to understand the educational process and the issue of integration of Africandescendants in this reality. We clarify that the discursive elements established in this study are corroborated by historical facts raised by the creation, and therefore, disclosure of certain stereotypes about African people, promoted by the Brazilian imaginary socioeconomic.
\end{abstract}

Keywords: Education; history; ethnicity; african descendants.

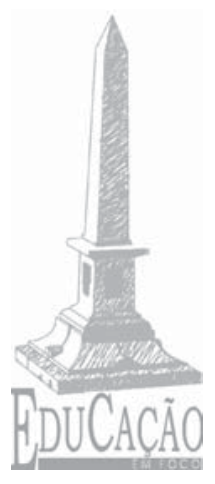

